\section{The Society of Industrial Pharmacy Students: A New Organization at the University of Houston}

\section{Dear Editor,}

Pharmacy students at the University of Houston are taking advantage of a unique organization devoted to raising interest in the field of industrial pharmacy and managed care. The organization is SIPS - the Society of Industrial Pharmacy Studentswhich came into being in 1998, the brainchild of a few pharmacy students who desired more information about the business side of pharmaceutical care. The mission of SIPS is to create an environment and provide opportunities for students and the pharmaceutical industry to interact and collaborate on mutually beneficial projects. The organization's goal is to provide students with detailed information regarding career opportunities within the pharmaceutical industry.

For the past 5 years, the officers of this very active organization have invited eminent individuals from across the country to visit the University of Houston and expound upon their life experiences to SIPS members. Over the years, SIPS has expanded its focus from providing a platform to learn about pharmaceutical companies to also learn about the areas of managed care and drug distribution. Some of the past speakers have been from companies such as Pfizer, Eli Lilly and Company, Merck, Pharmacia-Upjohn, Wyeth, AstraZeneca, Cardinal Health, McKesson, and Kelsey-Seybold Clinics.

The SIPS organization was the first at the College of Pharmacy to devote its efforts specifically to understanding issues facing the pharmaceutical industry and to delve into the effects managed care has on a pharmacist's professional responsibilities and growth. Special attention is given to recognizing that pharmacy is undergoing a controversial evolution and plays a pivotal role as drug and health care costs rise at exponential double-digit rates.

The University of Houston College of Pharmacy has an advanced pharmacy management program consisting of 4 semesters of didactic coursework devoted to bringing students "up to speed" on issues that affect the current pharmacy environment. The College also has a very active masters program in pharmacy administration. The addition of a joint PharmD/MS program that the College plans to offer further indicates that the progressive growth of managed care anticipated within pharmacy is recognized by academicians.

Why was it necessary to form such an organization? First, the lack of a strong industry presence on most pharmacy campuses, compounded by the lack of exposure to career opportunities within the pharmaceutical industry, triggered the need for a greater understanding of this growing area of pharmacy. Students in pharmacy schools across the country spend up to 6 years preparing to be pharmacists, with little interaction with prospective employers in the pharmaceutical industry. Most students opt to select traditional community (retail) or institutional (hospital) careers because of their constant exposure to them in their pharmacy training. The SIPS organization felt that students' exposure to the pharmaceutical industry would inter- est them in lucrative positions available in managed care.

Another main focus of the organization has been to clarify opportunities offered by the pharmaceutical industry. A misconception that SIPS tackled was that the pharmaceutical industry only offers sales representative jobs that utilize very little of the students' pharmacy education. In addition, students posed the question of why they should struggle in industry if all they had to do was dispense medications in a retail pharmacy and be more highly compensated for their time. Many students also believed that the pharmaceutical industry only offered better positions if students furthered their education and became research scientists. Since drug discovery and pharmaceutical research is traditionally not highly emphasized in most pharmacy schools, students are not even aware of what research entails. Thus, the SIPS organization addressed these misconceptions. The SIPS organization not only provides this industry exposure but is also a platform for communication between the students and the pharmaceutical industry.

The SIPS organization also strives to help students understand the fundamental reasons for rising health care costs and the importance of managed care in this process. It addresses this issue by inviting pharmacists from managed care environments to visit the University of Houston. As health care costs increase and baby boomers age, managed care plays a vital role in the evolution of health care. It does so by taking on more responsibility and reining in costs in order to provide a broader range of services to a greater population of people. PricewaterhouseCoopers published a report in April 2002 that investigated what fuels the rising cost of health care. Several reasons for an increase in costs were identified, including drug and provider costs and inflated legal expenses. The report also projected the impact managed care will have over the next 5 years in controlling costs. These are some of the topics that are discussed by presenters at the SIPS monthly presentation seminars.

Other SIPS seminar topics include the role of the pharmacist in managed care formulary development, drug approval by pharmacy and therapeutic committees, the pharmacist's role in drug protocol development, and promotion of evidence-based medicine. By participating in formulary selection and guideline implementation, pharmacists can have a profound influence on patient outcomes and health care costs.

What are SIPS students doing to further prepare themselves for entry into the field of managed care? As Society members, students can explore the various opportunities available to them via informal meetings and lunches with pharmaceutical companies. Students who want to learn about the business side of pharmacy now have a formal process in which to be mentored by fellow pharmacists in the industry. The SIPS organization is now collaborating with managed care and industry to develop company partners for future collaborative efforts that further the goals of SIPS members.

Since 1998, the SIPS organization has hosted many events, including arranging industry field trips, promoting representation at conferences, inviting eminent speakers for presentation, developing career workshops, and endorsing the overall posi- 
tive aspects of careers in the pharmaceutical industry.

Sujit S. Sansgiry, PhD

Assistant Professor and Faculty Co-advisor for SIPS

Amy Sorensen

PharmD candidate and SIPS Secretary, 2002-2003

University of Houston College of Pharmacy

Houston, Texas

E-mail:SSansgiry@uh.edu

\section{Shortcomings in Pharmacy Benefit Forecasting - Interferon Beta Products}

\section{Dear Editor,}

I read with great interest the article by Meyer and colleagues in the March/April, 2003 issue of the Journal. ${ }^{1}$ I am very concerned that the authors may not have used complete information and may have made inappropriate assumptions in their research. My concerns are as follows:

1. While the Evidence for Interferon Dose Effect: EuropeanNorth American Comparative Efficacy (EVIDENCE) trial showed a $12 \%$ greater number of relapse-free patients for interferon beta-la (Rebif-referred to as IBla2 by the authors) versus Interferon beta-la (Avonex-referred to as IBlal by the authors) at 24 weeks, the data showed a $1 \%$ greater number of relapse-free patients favoring IBlal at 48 weeks. ${ }^{2}$ Inferring long-term clinical effectiveness, especially with a lifelong disease like multiple sclerosis, from short-term study findings can be fraught with difficulty.

2. No consideration is given by the authors to the costs of treating the increased number of side effects attributable to use of IBla2 versus IBlal as demonstrated in the EVIDENCE trial. ${ }^{2}$ These include higher frequency of occurrence of injection site disorders, liver abnormalities (including elevated ALT and AST), and white blood cell abnormalities (including leukopenia).

3. In estimating the incremental cost to a plan of adopting IBla2, the authors deduct administrative costs related to managing multiple products on formulary. The assumption is that IBla2 is adopted in place of other approved products, not in addition to these products. As such, the savings in question are attributable to the plan's decision to adopt an exclusive formulary, not to IBla2 per se. Similar savings would accrue to the plan if exclusive status were awarded to IBlal or to any other approved product. The true incremental cost to a health plan of placing a new patient on IBla2 versus other products in a nonexclusive formulary setting is therefore significantly higher than the \$.05 PMPM cited by the authors.

4. Incidence of neutralizing antibodies was much higher in IBla2-treated versus IBlal-treated subjects in EVIDENCE. In fact, at 48 weeks, $25 \%$ of IBla2 patients had neutralizing antibody titers greater than or equal to 20 versus $2 \%$ of
IBlal-treated patients. ${ }^{2}$ While the clinical significance of antibodies has not been completely elucidated, many clinicians are now testing for neutralizing antibodies and discontinuing interferon beta therapy when the antibody titer increases to greater than 20 .

5. IBlal is the only interferon beta product to have shown positive effects on brain atrophy $y^{3-5}$ and cognitive dysfunction $^{6-8}$ in clinical trials. These findings may correlate to better long-term treatment success.

6. The claim in the article that assumes $80 \%$ of newly diagnosed multiple sclerosis patients would utilize IB1a2 appears to have no basis in fact. Market share in this category has not changed appreciably since IBla2's entry. Due to mounting concern over neutralizing antibodies, it is highly doubtful that its market share will attain the projections reported by the authors.

In conclusion, pharmacoeconomic modeling is based upon certain assumptions, and the pharmacy-budget impact analysis in the article by Drs. Meyer, Phipps, Cooper, and Wright did not properly represent the known clinical evidence for the treatment of multiple sclerosis or common practices used in drug benefit administration.

\section{Sheldon J. Rich, RPh, PhD \\ President, SJR Associates, LLC, West Bloomfield, Michigan Clinical Assistant Professor, University of Michigan Adjunct Assistant Professor, Wayne State University E-mail:SJRAssociates@aol.com}

\section{DISCLOSURES}

There was no specific funding for the preparation of this letter. Dr. Rich has served as a consultant to Biogen, Inc; Berlex; and Teva.

\section{REFERENCES}

1. Meyer CM, Phipps R, Cooper D, Wright A. Pharmacy benefit forecast for a new interferon beta-la for the treatment of multiple sclerosis: development of a first-line decision tool for pharmacy-budget planning using administrative claims data. J Managed Care Pharm. 2003;9(2):168-74.

2. U.S. Food and Drug Administration Center for Drug Evaluations and Research. Department of Health and Human Services, Orphan Product Development. Memorandum: March 7, 2003. Analysis of exclusivity issues raised in the Serono BLA for Rebif.

3. Rudick RA, Fisher E, Lee JC, Simon J, Jacobs L, for the Multiple Sclerosis Collaborative Research Group. Use of the brain parenchymal fraction to measure whole brain atrophy in relapsing-remitting MS. Neurology. 1999;53:1698-704.

4. Miller et al. MRI monitoring of cerebral atrophy during a placebo-controlled trial of interbeta lb in secondary progressive MS. Neurology. 2000;54(suppl 3): A86.

5. Jones et al. MRI cerebral atrophy in relapsing-remitting MS: results from the PRISMS trial. Neurology. 2001;56(suppl 3):A379.

6. Fischer JS, Priore RL, Jacobs LD, Cookfair DL, Rudick RA, for the Multiple Sclerosis Collaborative Research Group. Neuropsychological effects of interferon b-la in relapsing multiple sclerosis. Ann Neurol. 2000;48:885.

7. Pliskin NH, Hamer DP, Goldstein DS, et al. Improved delayed visual reproduction test performance in multiple sclerosis patients receiving interferon beta-1b. Neurology. 1996;47:1463-68. 